\title{
Systematic review of aquatic physical exercise programs on functional fitness in older adults
}

\author{
José Fuentes Lopez (1), Rubén Vidal Espinoza (2), Fernando Alvear-Vasquez (3), \\ Lucila Sanchez Macedo (1), Dony Mamani Velasquez (1), Wily Rivera Pacco (1), \\ Marco Cossio Bolaños (4,5), Rossana Gómez Campos (6)
}

(1) Instituto de Investigación en Ciencias de la Educación (IICE), Universidad Nacional del Altiplano de Puno, Puno, Perú; (2) Universidad Católica Silva Henriquez, Santiago, Chile; (3) Universidad de Valencia, Valencia, España; (4) Departamento de Ciencias de la Actividad Física, Universidad Católica del Maule, Talca, Chile; (5) Centro de Investigación CINEMAROS SAC, Arequipa, Perú; (6) Departamento de Diversidad e Inclusividad Educativa, Universidad Católica del Maule, Talca, Chile.

This article is distributed under the terms of the Creative Commons Attribution Noncommercial License (CC BY-NC 4.0) which permits any noncommercial use, distribution, and reproduction in any medium, provided the original author(s) and source are credited.

\begin{abstract}
The practice of physical exercise is recommended in the prevention of the deterioration of neuromuscular functions in aging. The objectives of this systematic review were to describe the protocols used and the functional fitness indicators evaluated in aquatic exercise programs in adults aged 50 to 80 years. The Pubmed database was used. The keywords were: 1) Physical exercise program or protocols or duration or type of exercise or aquatic exercise, frequency or intensity or indicators; 2) Adults or older adults; 3) Training or indicators, functional fitness, physical fitness. The search strategy considered the components of the Population, Interventions, Comparators, Outcomes, and Study design (PICOS) tool. Nine experimental studies were identified. These studies developed protocols to improve functional fitness in adults aged 50 to 80 years. They were based on sessions of 2 to 5 per week, the work time per session was 30 to 60min, intensities varied between 50 to $95 \%$ and totaled between 4 to 24 weeks of intervention. The activities were based on aquatic gymnastic exercises aimed at muscular strengthening of the upper and lower extremities, as well as coordination, balance, agility, cycling and walking exercises submerged in water. The protocols developed to improve functional fitness in adults aged 50 to 80 years were based on general physical exercise prescription guidelines (frequency, duration, intensity and type of activity). The application of aquatic exercises based on gymnastic exercises can provoke positive responses on functional fitness if worked at least 2 to 5 times per week, 30 to $60 \mathrm{~min} /$ day and at intensities of 50 to $95 \%$. These systematized indicators can be used by professionals working with adults to create and promote aquatic programs to improve functional fitness.
\end{abstract}

Key Words: Intervention programs; functional fitness; aquatic activities; adults.

Eur J Transl Myol 31 (4): 10006, 2021 doi: 10.4081/ejtm.2021.10006

Physical exercise is defined as a subset of structured physical activities designed to improve cardiorespiratory fitness, cognitive function, balance, flexibility and muscular strength. ${ }^{1}$ It is widely known as one of the therapeutic strategies that helps to minimize the detrimental effects on the musculoskeletal system generated by aging. ${ }^{2}$ In general, physical exercise fulfills various functions at all stages of life, especially it is recommended to prevent the deterioration of neuromuscular functions during aging. ${ }^{3}$ For example, at advanced ages it preserves functional independence, promotes weight control, improves and maintains quality of life, functional capacity and emotional well-being. ${ }^{4}$ In essence, older adults are losing their performance in functional fitness, this involves alterations at the muscular level due to loss of strength, osteoarticular deficiencies that limit their ability to move, increasing the risk of falls and fractures, reduction in pulmonary and cardiovascular capacity, so their ability to make physical efforts are limited, affecting their quality of life and daily functional performance. ${ }^{5-7}$ Currently, several studies have shown that physical activity programs based on aquatic exercise have produced significant positive 
changes in the functional fitness of older adults. ${ }^{8-11}$ Therefore, it is necessary for aging populations to participate in these intervention programs to improve their levels of agility, balance, coordination, strength, flexibility and speed, ${ }^{12}$ as well as, muscle power, respiratory muscle function, postural stability, and aerobic capacity. ${ }^{13}$ Aquatic programs are defined as a set of exercises performed in water, mainly in upright position, with or without music, and in shallow or deep water, ${ }^{14}$ or even involves any type of physical exercise that is practiced immersed in water. ${ }^{13}$ These programs are presented as an important alternative intervention, where water supports body weight and minimizes the fear of falls in older adults, ${ }^{15}$ promoting and improving functional fitness, health and quality of life of the older adult. ${ }^{4}$ Studies have currently shown that lack of physical exercise in older adults increases the risk of developing chronic noncommunicable diseases, which, influences functional independence, cognitive, intrinsic capacity, mobility, musculoskeletal pain, risk of falls, fractures, depression, quality of life among others. ${ }^{1,16}$ Thus a systematic review was proposed around the question: What will be the protocols to be used and the functional fitness indicators to be evaluated in aquatic exercise programs for older adults?

To answer this question, this study aimed to describe the published protocols used and the functional fitness indicators evaluated in aquatic exercise programs in adults aged 50 to 80 years.

\section{Materials and Methods}

A systematic review literature study was conducted in accordance with the Preferred Reporting Items for Systematic Reviews and Meta-Analyses (PRISMA) statement, ${ }^{17}$ which was developed to ensure complete reporting of systematic reviews. To achieve relevance the articles included the following keywords: 1. Physical exercise program or protocols or duration or type of exercise or aquatic exercise, frequency or intensity or indicators; 2. Adults or older adults; 3. Training or indicators, functional fitness, physical fitness. Initially, all keywords were used together, using the boileans "and"

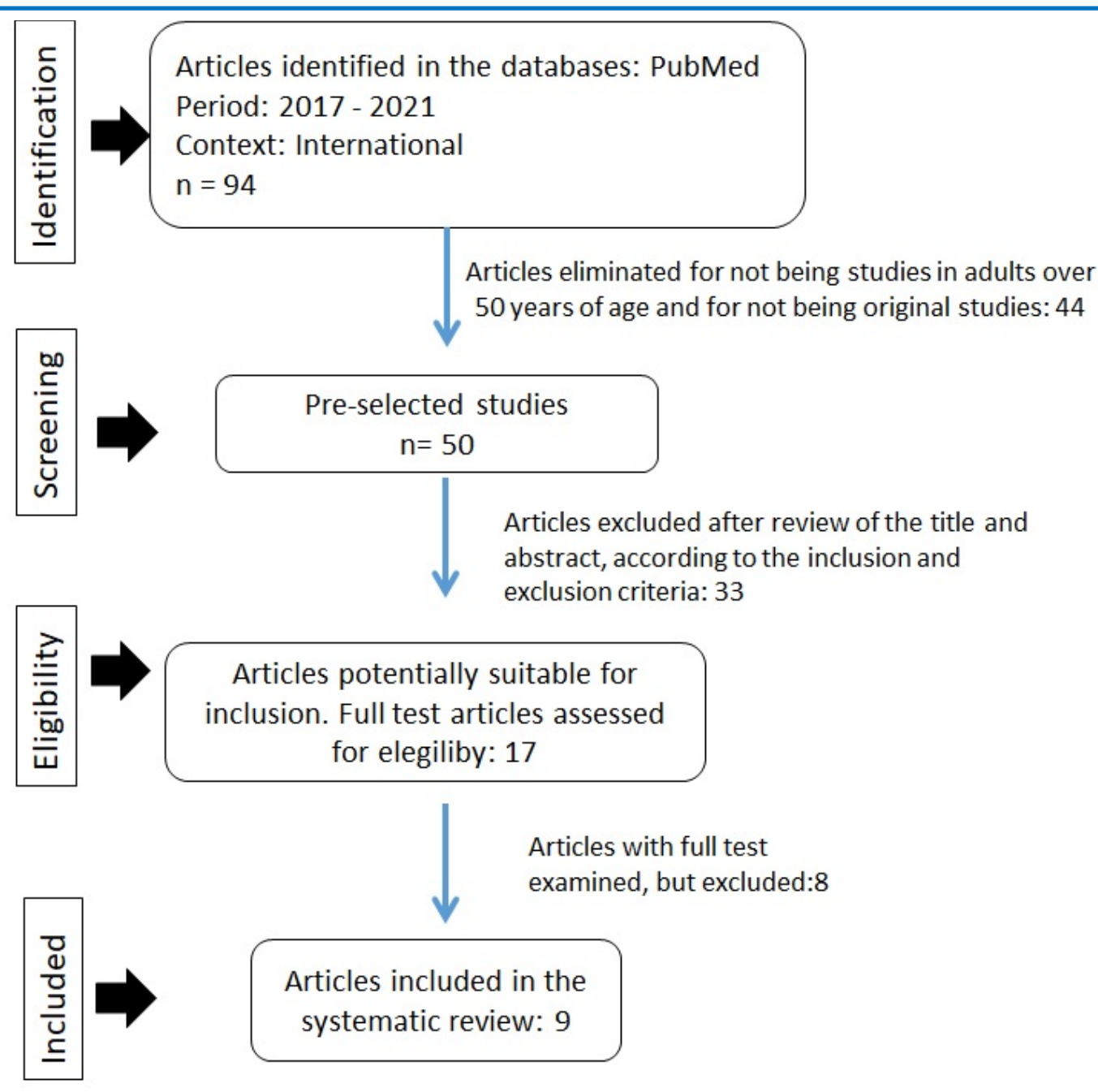

Fig 1. PRISMA flow chart for the systematization of original articles 2017-2021. 
Table 1. Methodological characteristics of the systematized studies.

\begin{tabular}{|c|c|c|c|c|c|c|}
\hline $\mathbf{N}^{\circ}$ & Authors & Year & Title & Groups & Gender & Age range \\
\hline 1 & Alcalde et al. $^{2}$ & 2017 & $\begin{array}{l}\text { Effect of aquatic physical therapy on pain } \\
\text { perception, functional capacity and quality } \\
\text { of life in older people with knee } \\
\text { osteoarthritis: study protocol for a } \\
\text { randomized controlled trial }\end{array}$ & $\begin{array}{l}\text { EG } \\
\text { CG }\end{array}$ & $\mathrm{NE}$ & $\sim 60$ years \\
\hline 2 & Silva et al. ${ }^{11}$ & 2019 & $\begin{array}{l}\text { Effects of aquatic exercise on mental } \\
\text { health, functional autonomy and oxidative } \\
\text { stress in depressed elderly individuals: A } \\
\text { randomized clinical trial }\end{array}$ & $\begin{array}{l}\text { EG1 } \\
\text { EG2 }\end{array}$ & $\begin{array}{l}\mathrm{F} \\
\mathrm{M}\end{array}$ & $50-80$ years \\
\hline 3 & $\begin{array}{l}\text { Aboarrage et } \\
\text { al. }{ }^{9}\end{array}$ & 2018 & $\begin{array}{l}\text { A High-Intensity Jump-Based Aquatic } \\
\text { Exercise Program Improves Bone Mineral } \\
\text { Density and Functional Fitness in } \\
\text { Postmenopausal Women }\end{array}$ & $\begin{array}{l}\text { EG } \\
\text { CG }\end{array}$ & $\mathrm{F}$ & 57 - 75 years \\
\hline 4 & Lee et al. ${ }^{18}$ & 2018 & $\begin{array}{l}\text { The Effects of a Motorized Aquatic } \\
\text { Treadmill Exercise Program on Muscle } \\
\text { Strength, Cardiorespiratory Fitness, and } \\
\text { Clinical Function in Subacute Stroke } \\
\text { Patients: A Randomized Controlled Pilot } \\
\text { Trial }\end{array}$ & $\begin{array}{l}\text { EG } \\
\text { CG }\end{array}$ & $\begin{array}{l}\mathrm{F} \\
\mathrm{M}\end{array}$ & $60,5 \pm 12,9$ years \\
\hline 5 & Aidar et al..$^{19}$ & 2018 & $\begin{array}{l}\text { A randomized trial of the effects of an } \\
\text { aquatic exercise program on depression, } \\
\text { anxiety levels, and functional capacity of } \\
\text { people who suffered an ischemic stroke. }\end{array}$ & $\begin{array}{l}\text { EG } \\
\text { CG }\end{array}$ & $\begin{array}{l}\mathrm{F} \\
\mathrm{M}\end{array}$ & $\begin{array}{l}\text { GE: } 51.8 \pm 8.5 \text { years } \\
\text { GC: } 52.7 \pm 6.7 \text { years }\end{array}$ \\
\hline 6 & Silva et al. ${ }^{8}$ & 2018 & $\begin{array}{l}\text { Water-based aerobic and combined } \\
\text { training in elderly women: Effects on } \\
\text { functional capacity and quality of life. }\end{array}$ & $\begin{array}{l}\text { EG1 } \\
\text { EG2 } \\
\text { CG }\end{array}$ & $\mathrm{F}$ & $65.0 \pm 4.0$ years \\
\hline 7 & $\begin{array}{l}\text { Moreira et } \\
\text { al. }{ }^{10}\end{array}$ & 2017 & $\begin{array}{l}\text { Impact of two hydrogymnastics class } \\
\text { methodologies on the functional capacity } \\
\text { and flexibility of elderly women }\end{array}$ & $\begin{array}{l}\text { EG1 } \\
\text { EG2 } \\
\text { CG }\end{array}$ & $\mathrm{F}$ & 50 - 70 years \\
\hline 8 & Han and $\operatorname{Im} .{ }^{20}$ & 2018 & $\begin{array}{l}\text { Aquatic Treadmill Exercise Program on } \\
\text { Cardiorespiratory Fitness and Walking } \\
\text { Endurance in Subacute Stroke Patients: A } \\
\text { pilot trial. }\end{array}$ & $\begin{array}{l}\text { EG1 } \\
\text { EG2 }\end{array}$ & $\begin{array}{l}\mathrm{F} \\
\mathrm{M}\end{array}$ & $\begin{array}{c}\text { EG1:62.4 } \pm 12.7 \text { years } \\
\text { EG2: } 9.4 \pm 14.2 \text { years }\end{array}$ \\
\hline 9 & Costa et al. ${ }^{21}$ & 2018 & $\begin{array}{l}\text { Water-based aerobic training improves } \\
\text { strength parameters and cardiorespiratory } \\
\text { outcomes in elderly women }\end{array}$ & $\begin{array}{l}\text { EG1 } \\
\text { EG2 } \\
\text { CG }\end{array}$ & $\mathrm{F}$ & 60 - 75 years \\
\hline
\end{tabular}

Legend: EG: experimental group, CG: control group, M: male, F: female, NS: not specified.

and "or" to order them. Subsequently, these words were grouped into two or three, and a new search was performed, such as, for example, aquatic exercise and older adult and functional fitness. The terms in the search strategy were also matched (e.g., aquatic exercise or training). These terms were searched for in the title, abstract, and keywords of manuscripts. In addition, a manual search was performed for articles that were not in the searched database, e.g., studies cited by other manuscripts. Due to differences in terminology and writing style, a list of synonyms for the terms of interest was used to identify all relevant articles. Studies that included systematic reviews were excluded from the analysis. The search was limited to articles that investigated adults older than 50 years of age. Articles were also excluded if they met the eligibility criteria for this study, but the full version was not accessible (because they were not available electronically or in hard copy or were requested from the authors but not sent). The initial search strategy identified articles describing protocols for aquatic exercise programs in adults over 50 years of age. An electronic search was conducted in the database: PubMed. The electronic search was conducted during the period of 1 month from May 1st to 31st, 2021. Targeted searches in the most cited journals and authors and in the reference lists of articles ensured that all relevant articles were located. The basis of the search strategy were the components of the Population, Interventions, Comparators, Outcomes, and Study design (PICOS) tool. Being P: Adults over 50 years of age participating in aquatic physical exercise programs; I: Aquatic exercise programs that improve functional 
Aquatic physical exercise programs for fitness of older adults

Eur J Transl Myol 31 (4): 10006, 2021 doi: 10.4081/ejtm.2021.10006

Table 2. Analysis of the methodological quality of the articles selected for this systematic review.

\begin{tabular}{|c|c|c|c|c|c|c|c|c|c|c|}
\hline $\mathbf{N}$ & Criteria & $\begin{array}{c}\text { Alcalde et } \\
\text { al. }^{2}\end{array}$ & $\begin{array}{c}\text { Silva et } \\
\text { al. }^{8}\end{array}$ & $\begin{array}{c}\text { Aboarrage } \\
\text { et al. }^{9}\end{array}$ & $\begin{array}{c}\text { Lee et } \\
\text { al. }^{18}\end{array}$ & $\begin{array}{c}\text { Aidar et } \\
\text { al. }^{19}\end{array}$ & $\begin{array}{c}\text { Silva et } \\
\text { al. }^{11}\end{array}$ & $\begin{array}{c}\text { Moreira } \\
\text { et al. }{ }^{10}\end{array}$ & $\begin{array}{l}\text { Han and } \\
\operatorname{Im}^{20} \\
\end{array}$ & $\begin{array}{c}\text { Costa et } \\
\text { al. }^{21}\end{array}$ \\
\hline 1 & $\begin{array}{l}\text { Randomization } \\
\text { sequence generation }\end{array}$ & Yes & No & Yes & Yes & Yes & Yes & Yes & Yes & Yes \\
\hline 2 & Allocation Secrecy & Yes & No & No report & Yes & No report & Yes & Yes & Yes & Yes \\
\hline 3 & $\begin{array}{l}\text { Adhesion of the } \\
\text { endorsed }\end{array}$ & No report & Yes & No report & Yes & Yes & No report & No report & No report & Yes \\
\hline 4 & $\begin{array}{l}\text { Attachment of the } \\
\text { professionals who } \\
\text { applied the } \\
\text { intervention }\end{array}$ & No report & $\begin{array}{l}\text { No } \\
\text { report }\end{array}$ & No report & Yes & No report & No report & No report & No report & Yes \\
\hline 5 & $\begin{array}{l}\text { Blindness of the } \\
\text { assessors of the } \\
\text { waste }\end{array}$ & Yes & $\begin{array}{l}\text { No } \\
\text { report }\end{array}$ & No report & Yes & No report & Yes & No report & No report & Yes \\
\hline 6 & $\begin{array}{l}\text { Similar groups in the } \\
\text { initial evaluation }\end{array}$ & Yes & No & Yes & Yes & No report & No report & No report & Yes & Yes \\
\hline 7 & $\begin{array}{l}\text { Criteria for selection } \\
\text { of participants }\end{array}$ & Yes & Yes & Yes & Yes & Yes & Yes & Yes & Yes & Yes \\
\hline 8 & $\begin{array}{l}\text { Analysis by } \\
\text { intention to treat }\end{array}$ & No report & Yes & Yes & Yes & No report & Yes & Yes & Yes & Yes \\
\hline 9 & $\begin{array}{l}\text { Static comparison } \\
\text { between groups }\end{array}$ & Yes & Yes & Yes & Yes & Yes & Yes & Yes & Yes & Yes \\
\hline \multirow[t]{2}{*}{10} & $\begin{array}{l}\text { Description of losses } \\
\text { and exclusions }\end{array}$ & No report & Yes & No report & Yes & Yes & Yes & No report & No report & Yes \\
\hline & PEDro scale scoring & 6 & 5 & 5 & 10 & 5 & 7 & 5 & 6 & 10 \\
\hline
\end{tabular}

fitness; C: Present an experimental group or two experimental groups subjected to different types of activity, intensity, frequency and number of weeks, with or without a control group; $\mathrm{O}$ : describe the aquatic exercise program that elicited positive responses on functional fitness; S: experimental studies. The assessment of methodological quality was performed independently by two reviewers (MC, RG), who analyzed the selected studies of this systematic review and resolved disagreements in analysis by consensus. The methodological quality review was performed using the Physiotherapy Evidence Database (PEDro) scale (from de Morton) ${ }^{22}$ based on the Delphi list. ${ }^{23}$ This scale has 10 scoring questions, and each criterion is scored according to its presence (one point) or absence (zero points) in the study in question. The following items were considered: generation of the randomization sequence; confidentiality of allocation; blinding of those evaluated; blinding of the professionals and evaluators who applied the intervention/evaluation; blinding of the evaluators of the study results; similar groups at baseline; participant selection criteria; intention-to-treat analysis; statistical comparison between groups; description of losses and exclusion. Data extraction from each article was performed using a structured script that included the following points: sample (age range and sex of study participants), groups considered (control group and experimental group), protocol performed (content and activity developed, duration, intensity, frequency, total weeks). A first reviewer performed the data extraction, and the second reviewer verified the data extraction, ensuring that the data collected were accurate and complete. For the presentation of the results of the articles, the descriptive information of the protocols developed in the studies was used, which allowed us to quantify the indicators of functional fitness evaluated by the programs in each study.

\section{Results}

Figure 1 shows the PRISMA flow chart showing the study selection process developed. Ninety-four studies were identified worldwide, which were considered as possible potential studies for systematization. Subsequently, 44 studies were eliminated as they were not original studies and in adults over 50 years of age. In the next stage, the titles and abstracts were read, considering the inclusion and exclusion criteria, and 33 articles were eliminated. In the third stage, of the 17 eligible studies, which were read in their entirety, 8 that were not experimental were eliminated. Finally, 9 articles were considered in this review (Table 1). All studies have experimental and control groups and the age range oscillates from 50 to 80 years old. Four studies have been conducted only in female, one study does not specify the gender of the investigated groups and 4 studies have been conducted in both genders. The results of the quality analysis of the articles are shown in Table 2. All the studies included in this systematic review presented 
Table 3. Protocols used and activities developed in the aquatic physical exercise.

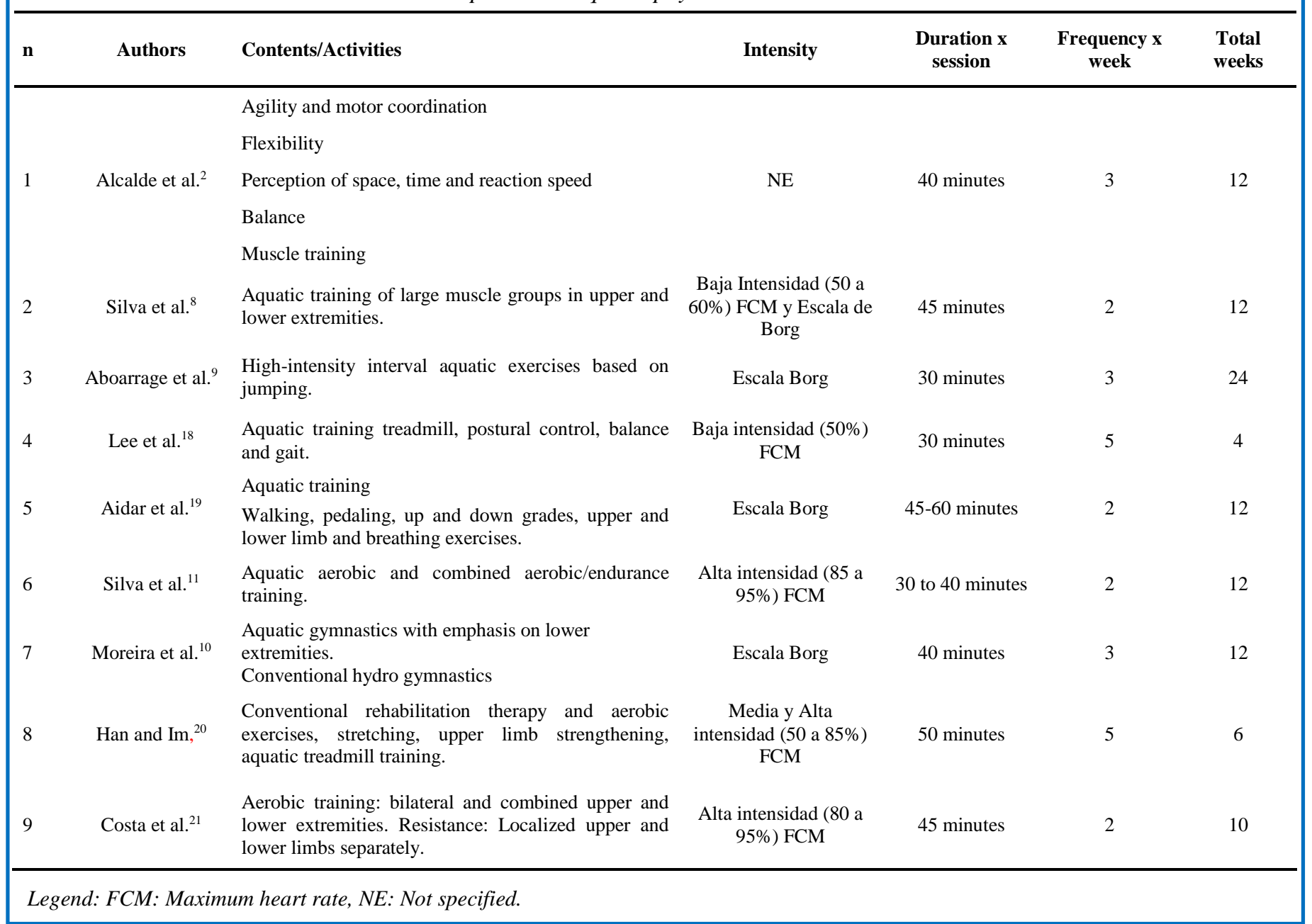

participant selection criteria and included statistical comparison between groups. A total of $88.9 \%$ indicated the randomization sequence; however, only $66.7 \%$ indicated that they considered the secrecy of group allocation. Likewise, four studies (44.4\%) considered the blinding of the professional who applied the intervention, hiding the identity of the group assignments from the researchers who collected and analyzed the study variables. Evaluation of the methodological quality, through the PEDro scale, showed that the two studies with the highest scores were Lee et al., ${ }^{18}$ and Costa et al., ${ }^{21}$ (10 points), followed by Silva et al., ${ }^{8}$ (7 points); Alcalde et al., ${ }^{1}$ and Ham and $\mathrm{Im},{ }^{20}$ (6 points); Silva et al., ${ }^{11}$ Aboarrage et al., ${ }^{9}$ Aidar et al., ${ }^{19}$ and Moreira et al., ${ }^{10}$ (5 points) on this scale. Table 3 illustrates the protocols used in the 9 systematized studies (activities, intensity, duration, frequency and total weeks). In general, the duration of the programs ranged from 30 to $60 \mathrm{~min} / \mathrm{session}$, the frequency ranged from 2 to 5 sessions per week, the intensity was monitored by means of the maximum heart rate (MHR) with a percentage of 50 to $95 \%$ and the Borg subjective scale. The duration of the intervention programs in total varied from 4 to 24 weeks and the activities developed were based on aquatic gymnastic exercises, emphasizing the upper and lower extremities, coordination exercises, balance, agility, cycling and walking. The functional fitness indicators that were evaluated before and after the aquatic program interventions are described in Table 4. After systematization, 09 indicators were identified that were evaluated by the studies (functional mobility, balance, leg strength, dad, agility, cardiorespiratory fitness, motor function, gait, and arm strength). Of these, 4 studies mostly evaluated 3 indicators (functional mobility, balance, and leg strength), however, the other studies have evaluated between 3 to 5 indicators (flexibility, agility, cardiorespiratory fitness, motor function, gait, and arm strength).

\section{Discussion}

The results of this study have shown that the protocols used in the 9 systematized studies are fundamentally based on the development of aquatic gymnastics exercises. These focus on muscular strengthening of the upper and lower extremities, as well as coordination, balance, agility, cycling and walking exercises 
Table 4. Functional fitness indicators evaluated in aquatic physical exercise programs in adults aged 50 to 80 years.

\begin{tabular}{|c|c|c|c|c|c|c|c|c|c|}
\hline \multirow{2}{*}{ Variables evaluated } & \multicolumn{9}{|c|}{ Studies } \\
\hline & 1 & 2 & 3 & 4 & 5 & 6 & 7 & 8 & 9 \\
\hline Functional mobility & $\mathrm{X}$ & $\mathrm{X}$ & $\mathrm{X}$ & & $\mathrm{X}$ & $\mathrm{X}$ & $\mathrm{X}$ & & \\
\hline Flexibility & $\mathrm{X}$ & $\mathrm{X}$ & & & & & $\mathrm{X}$ & & \\
\hline Balance & & $\mathrm{X}$ & $\mathrm{X}$ & $\mathrm{X}$ & $\mathrm{X}$ & $\mathrm{X}$ & $\mathrm{X}$ & & \\
\hline Agility & & & $\mathrm{X}$ & & $\mathrm{X}$ & $\mathrm{X}$ & $\mathrm{X}$ & & \\
\hline Leg strength & & & $\mathrm{X}$ & $\mathrm{X}$ & $\mathrm{X}$ & $\mathrm{X}$ & $\mathrm{X}$ & & $\mathrm{X}$ \\
\hline Cardiorespiratory fitness & & & & $\mathrm{X}$ & & $\mathrm{X}$ & & $\mathrm{X}$ & $\mathrm{X}$ \\
\hline Motor function & & & & $\mathrm{X}$ & & & & & \\
\hline Gait & & & & & $\mathrm{X}$ & $\mathrm{X}$ & $\mathrm{X}$ & $\mathrm{X}$ & \\
\hline Arm strength & & & & & & & & & $\mathrm{X}$ \\
\hline
\end{tabular}

Legend: 1: Alcalde et al. ${ }^{2} ;$ : Silva et al. ${ }^{8}$; $3:$ Aboarrage et al. ${ }^{9} ;$ 4: Lee et al. ${ }^{18} ; 5$ : Aidar et al. ${ }^{19} ;$ : Silva et al. ${ }^{11}$; $7:$ Moreira et al. ${ }^{10}$; 8: Han and Im, ${ }^{20}$; : Costa et al..$^{21}$

submerged in water. In fact, the literature reports that aquatic intervention programs include various types of exercises, such as lower and upper limb training and strengthening, aerobic, balance, walking, endurance resistance, and flexibility exercises, ${ }^{2,8,11,19}$ which have been fully considered by the 9 systematized studies. These aquatic activities have to do with the development of varied types of motor practices, which have to do with educational, competitive, utilitarian, recreational, preventive, therapeutic, training and maintenance objectives. ${ }^{24}$.In general, these aquatic activities developed in aging populations provide a low-impact and lightweight environment where people can exercise safely, ${ }^{12}$ where buoyancy, pressure, resistance and water temperature maximize the effectiveness of aquatic exercise, allowing light and safe body movements. ${ }^{25}$ Regarding the protocols used, the 9 systematized studies have reported varied intensities, frequencies and durations of the intervention programs. These were developed from 2 to 5 times per week, with intensities from 50 to $95 \%$ (low, medium and high), with a duration of 30 to 60 minutes per session and with a duration of 4 to 24 weeks. These findings of description of aquatic physical exercise, are consistent with that described by Barrow et al., ${ }^{26}$ where they highlight that moderate intensity exercise, for 30-60 minutes, three times per week, can be considered an effective treatment for weight control and obesity-related musculoskeletal symptoms. Moreover, they are consistent with the general guidelines for physical exercise prescription outlined by the position of the American College of Sports Medicine in which they are defined in terms of intensity, duration, frequency and type of activities to be performed in intervention programs. ${ }^{27}$ The indicators evaluated in systematized intervention programs have reported 9 variables (functional mobility, flexibility, balance, agility, leg strength, cardiorespiratory fitness, motor function, gait and arm strength). These studies have indicated in their results that aquatic exercises provoke positive responses on the functional fitness of the population between 50 and 80 years of age. In that sense, systematic and controlled training, widely evidence ostensible improvements in older adults, especially in functional autonomy. ${ }^{3}$ Specifically, the properties of water provide unique opportunities for rehabilitation through the hydrostatic and hydrodynamic principles of buoyancy and resistance, ${ }^{28}$ which consequently contributes to the reduction of pain, stiffness and difficulty in physical functions, as well as to the increase in the self-efficacy of motor movements in people with reduced mobility. ${ }^{29}$ Consequently, physically active older adults throughout life have higher levels in terms of physical and cognitive function, mobility, less musculoskeletal pain, lower risk of falls and fractures, depression, better quality of life, ${ }^{1}$ so the results of this systematization suggest the inclusion of aquatic exercises in programs for older adults to improve their functional capacity. Although, this study has some limitations, since the search for information was performed in only one database and covered 5 years (2017 to 2021), so future studies should expand the search for information not only in other databases, but also the range of years. On the other hand, this study can serve as a baseline to promote and propose aquatic intervention programs for older adults, as well as to compare the criteria used to prescribe physical exercise. Based on the results obtained, this study concludes that the protocols developed to improve functional fitness in adults aged 50 to 80 years were based on general physical exercise prescription guidelines (frequency, duration, intensity and type of activity). The application of aquatic activities based on gymnastic exercises can provoke positive responses on functional fitness if performed at least 2 to 5 times per week, 30 to $60 \mathrm{~min} /$ day and at intensities of 50 to $95 \%$.

In conclusion, these systematized indicators can be used by professionals working with older adults to create and promote aquatic programs to improve their functional fitness. 


\section{List of acronyms}

MHR - maximum heart rate

PICOS - population, interventions, comparators, outcomes, study

PEDro - Physiotherapy Evidence Database

PRISMA - preferred, reporting, items for systematic reviews and metaanalyses

\section{Contributions of Authors}

JFL, MCB, RVE, FAV, RGC: conception, design, drafting of the manuscript, analysis and interpretation of the data, critical review and final approval of the version to be published, agreement to be responsible for all aspects of the work to ensure that issues related to the accuracy or completeness of any part of the work are adequately investigated and resolved; MCB, RGC, RVE, FAV: critical review of important intellectual content; and final approval of the version to be published; JFL, RVE, LSM, DMV, WRP, systematization of the studies, critical review and final approval of the version to be published.

\section{Acknowledgments}

Special recognition to the Universidad Nacional del Altiplano, Puno, Perú.

\section{Funding}

None

\section{Conflict of Interest}

The authors declare no competing interests.

\section{Ethical Publication Statement}

We confirm that we have read the Journal's position on issues involved in ethical publication and affirm that this report is consistent with those guidelines.

\section{Corresponding Author}

Rossana Gómez Campos, PhD, Av. San Miguel s/n Talca, Chile.

ORCID iD: 0000-0001-6509-5707

E-mail: rossaunicamp@gmail.com

E-mails and ORCID iD of co-authors

Jose Fuentes Lopez: jofuelo@hotmail.com

ORCID iD: 0000-0002-6699-1439

Ruben Vidal-Espinoza: rvidale@gmail.com

ORCID iD: 0000-0002-8593-5248

Fernando Alvear-Vasquez:

fernandoalvearvasquez@gmail.com

ORCID iD: 0000-0002-9461-1384.

Lucila Sanchez Macedo: luceritonet@hotmail.com

ORCID iD: 0000-0003-0812-5230

Dony Mamani Velasquez: dmamani@hotmail.com

ORCID iD: 0000-0003-2024-3205

Wily Rivera Pacco: wrivera@hotmail.com

ORCID iD: 0000-0001-5008-7448

Marco Cossio-Bolaños: mcossio1972@hotmail.com ORCID iD: 0000-0001-7230-9996

\section{References}

1. Bangsbo J, Blackwell J, Boraxbekk CJ, Caserotti P, Dela F, Evans AB, Jespersen AP, Gliemann L, Kramer AF, Lundbye-Jensen J, Mortensen EL, Lassen AJ, Gow AJ, Harridge SDR, Hellsten Y, Kjaer M, Kujala UM, Rhodes RE, Pike ECJ, Skinner T, Skovgaard T, Troelsen J, Tulle E, Tully MA, van Uffelen JGZ, Viña J. Copenhagen Consensus statement 2019: physical activity and ageing. Br J Sports Med. 2019 Jul;53(14):856-858. doi: 10.1136/bjsports-2018-100451. Epub 2019 Feb 21.

2. Alcalde GE, Fonseca AC, Bôscoa TF, Gonçalves MR, Bernardo GC, Pianna B, Carnavale BF, Gimenes C, Barrile SR, Arca EA. Effect of aquatic physical therapy on pain perception, functional capacity and quality of life in older people with knee osteoarthritis: study protocol for a randomized controlled trial. Trials. 2017 Jul 11;18(1):317. doi: 10.1186/s13063-017-2061-X.

3. Martínez PY, Hall López JA, Paredones Hernández A, Martin Dantas EH. Efecto de un programa de entrenamiento periodizado de ejercicio acuático sobre la autonomía funcional en adultas mayores. Nutrición Hospitalaria. 2015;31(1):351-6. . https://doi.org/10.3305/NH.2015.31.1.7857

4. Guerrero Y, Soomro N, Wilson G, Dam Y, Meiklejohn J, Simpson K, Smith R, Brand-Miller J, Simic M, O'Connor H, Mavros Y, Foroughi N, Poon T, Bradshaw K, March L, Vanwanseele B, Eckstein F, Fransen M, Bergamasco J, Anandacoomarasamy A, Singh MF. Train High Eat Low for Osteoarthritis study (THE LO study): protocol for a randomized controlled trial. J Physiother. 2015 Oct;61(4):217. doi: 10.1016/j.jphys.2015.05.020. Epub 2015 Aug 29.

5. Chacón-Serna MJ, Quino-Ávila AC, VallejoCastillo LF. Capacidad funcional del anciano relacionada con la actividad física. Revista Investigación en Salud Universidad de Boyacá. 2017 Jul 24;4(1):86-103. https://doi.org/10.24267/ 23897325.199

6. García GC, Castillo MD, González ME. Asociación del síndrome de temor a caerse, actividades y participación en los adultos mayores. Revista Mexicana de medicina física y rehabilitación. 2013;25(2):43-8. Retrieved from https://www. medigraphic.com/cgi-bin/new/resumen.cgi?IDAR TICULO $=47240$.

7. Ferrer SC, Nova ÁM, Barros MP, García LA, Cruz MV. Caracterización de las actividades básicas de la vida diaria en un grupo de adultos mayores institucionalizados. Rev salud mov. 2012; 4(1): 418. ISSN 2027-4548.

8. Silva MR, Alberton CL, Portella EG, Nunes GN, Martin DG, Pinto SS. Water-based aerobic and combined training in elderly women: Effects on functional capacity and quality of life. Exp 
Gerontol. 2018 Jun;106:54-60. doi: 10.1016/j.exger.2018.02.018. Epub 2018 Feb 21.

9. Aboarrage Junior AM, Teixeira CVS, Dos Santos RN, Machado AF, Evangelista AL, Rica RL, Alonso AC, Barroso JA, Serra AJ, Baker JS, Bocalini DS. A High-Intensity Jump-Based Aquatic Exercise Program Improves Bone Mineral Density and Functional Fitness in Postmenopausal Women. Rejuvenation Res. 2018 Dec;21(6):535-540. doi: 10.1089/rej.2018.2069. Epub 2018 Nov 28.

10. Moreira OC, Lopes GS, de Matos DG, MaziniFilho ML, Aidar FJ, Silva SF, de Oliveira CE. Impact of two hydrogymnastics class methodologies on the functional capacity and flexibility of elderly women. J Sports Med Phys Fitness. 2019 Jan;59(1):126-131. doi: 10.23736/ S0022-4707.17.07872-0. Epub 2017 Dec 15.

11. Silva LAD, Tortelli L, Motta J, Menguer L, Mariano S, Tasca G, Silveira GB, Pinho RA, Silveira PCL. Effects of aquatic exercise on mental health, functional autonomy and oxidative stress in depressed elderly individuals: A randomized clinical trial. Clinics (Sao Paulo). 2019;74:e322. doi: 10.6061/clinics/2019/e322. Epub 2019 Jun 27.

12. Martínez-Carbonell Guillamón E, Burgess L, Immins $\mathrm{T}$, Martínez-Almagro Andreo A, Wainwright TW. Does aquatic exercise improve commonly reported predisposing risk factors to falls within the elderly? A systematic review. BMC Geriatr. 2019 Feb 22;19(1):52. doi: 10.1186/s12877 -019-1065-7.

13. Waller B, Ogonowska-Slodownik A, Vitor M, Lambeck J, Daly D, Kujala UM, Heinonen A. Effect of therapeutic aquatic exercise on symptoms and function associated with lower limb osteoarthritis: systematic review with metaanalysis. Phys Ther. 2014 Oct;94(10):1383-95. doi: 10.2522/ptj.20130417. Epub 2014 Jun 5.

14. Yázigi F, Espanha M, Vieira F, Messier SP, Monteiro C, Veloso AP. The PICO project: aquatic exercise for knee osteoarthritis in overweight and obese individuals. BMC Musculoskelet Disord. 2013 Nov 13;14:320. doi: 10.1186/1471-2474-14320.

15. Chan K, Phadke CP, Stremler D, Suter L, Pauley T, Ismail F, Boulias C. The effect of water-based exercises on balance in persons post-stroke: a randomized controlled trial. Top Stroke Rehabil. 2017 May;24(4):228-235. doi: 10.1080/10749357. 2016.1251742. Epub 2016 Nov 3.

16. Taylor D. Physical activity is medicine for older adults. Postgrad Med J. 2014 Jan;90(1059):26-32. doi: 10.1136/postgradmedj-2012-131366. Epub 2013 Nov 19.

17. Moher D, Liberati A, Tetzlaff J, Altman DG; PRISMA Group. Preferred reporting items for systematic reviews and meta-analyses: the PRISMA statement. PLoS Med. 2009 Jul 21;6(7):e1000097. doi: 10.1371/journal.pmed. 1000097. Epub 2009 Jul 21.

18. Lee SY, Im SH, Kim BR, Han EY. The Effects of a Motorized Aquatic Treadmill Exercise Program on Muscle Strength, Cardiorespiratory Fitness, and Clinical Function in Subacute Stroke Patients: A Randomized Controlled Pilot Trial. Am J Phys Med Rehabil. 2018 Aug;97(8):533-540. doi: 10.1097/PHM.0000000000000920.

19. Aidar FJ, Jacó de Oliveira R, Gama de Matos D, Chilibeck PD, de Souza RF, Carneiro AL, Machado Reis V. A randomized trial of the effects of an aquatic exercise program on depression, anxiety levels, and functional capacity of people who suffered an ischemic stroke. J Sports Med Phys Fitness. 2018 Jul-Aug;58(7-8):1171-1177. doi: 10.23736/S0022-4707.17.07284-X. Epub 2017 May 9.

20. Han EY, Im SH. Effects of a 6-Week Aquatic Treadmill Exercise Program on Cardiorespiratory Fitness and Walking Endurance in Subacute Stroke Patients: A PILOT TRIAL. J Cardiopulm Rehabil Prev. 2018 Sep;38(5):314-319. doi: 10.1097/HCR. 0000000000000243.

21. Costa RR, Kanitz AC, Reichert T, Prado AKG, Coconcelli L, Buttelli ACK, Pereira LF, Masiero MPB, Meinerz AP, Conceição MO, Sbeghen IL, Kruel LFM. Water-based aerobic training improves strength parameters and cardiorespiratory outcomes in elderly women. Exp Gerontol. 2018 Jul 15;108:231-239. doi: 10.1016/j.exger.2018.04.022. Epub 2018 May 3.

22. de Morton NA. The PEDro scale is a valid measure of the methodological quality of clinical trials: a demographic study. Aust J Physiother. 2009;55(2):129-33. doi: 10.1016/s0004-9514(09).

23. Verhagen AP, de Vet HC, de Bie RA, Kessels AG, Boers M, Bouter LM, Knipschild PG. The Delphi list: a criteria list for quality assessment of randomized clinical trials for conducting systematic reviews developed by Delphi consensus. J Clin Epidemiol. 1998 Dec;51(12):1235-41. doi: 10.1016/s0895-4356(98)00131-070043-1.

24. Barbosa TM, Marinho DA, Reis VM, Silva AJ, Bragada JA. Physiological assessment of head-out aquatic exercises in healthy subjects: a qualitative review. J Sports Sci Med. 2009 Jun 1;8(2):179-89.

25. Carroll LM, Volpe D, Morris ME, Saunders J, Clifford AM. Aquatic Exercise Therapy for People With Parkinson Disease: A Randomized Controlled Trial. Arch Phys Med Rehabil. 2017 Apr;98(4):631-638. doi: 10.1016/j.apmr.2016.12. 006. Epub 2017 Jan 12.

26 Barrow DR, Abbate LM, Paquette MR, Driban JB, Vincent HK, Newman C, Messier SP, Ambrose KR, Shultz SP. Exercise prescription for weight management in obese adults at risk for osteoarthritis: synthesis from a systematic review. 


\section{Aquatic physical exercise programs for fitness of older adults}

Eur J Transl Myol 31 (4): 10006, 2021 doi: 10.4081/ejtm.2021.10006

BMC Musculoskelet Disord. 2019;20(1):610. https://doi.org/10.1186/s12891-019-3004-3.

27. Donnelly JE, Blair SN, Jakicic JM, Manore MM, Rankin JW, Smith BK; American College of Sports Medicine. American College of Sports Medicine Position Stand. Appropriate physical activity intervention strategies for weight loss and prevention of weight regain for adults. Med Sci Sports Exerc. 2009 Feb;41(2):459-71. doi: 10.1249/MSS.0b013e3181949333. Erratum in: Med Sci Sports Exerc. 2009 Jul;41(7):1532. PMID: 19127177.

28. Heywood S, McClelland J, Mentiplay B, Geigle P, Rahmann A, Clark R. Effectiveness of Aquatic Exercise in Improving Lower Limb Strength in
Musculoskeletal Conditions: A Systematic Review and Meta-Analysis. Arch Phys Med Rehabil. 2017 Jan;98(1):173-186. doi: 10.1016/j.apmr.2016.08. 472. Epub 2016 Sep 22..

29. Fertelli TK, Mollaoglu M, Sahin O. Aquatic exercise program for individuals with osteoarthritis: Pain, stiffness, physical function, self-efficacy. Rehabilitation Nursing. 2019;44(5):290-299. doi: 10.1097/rnj.0000000000000142.

Submission: July 28, 2021 Revision received: September 9, 2021 Accepted for publication: September 22, 2021 